\title{
openheart Research priorities in cardiovascular imaging
}

\author{
Guo Liang Yong (D) , Jonathan Weir-McCall (1) , ${ }^{2}$ Michael Wilson, ${ }^{3}$ Giles H Roditi, ${ }^{4}$ \\ Russell Bull, ${ }^{5}$ Michelle Claire Williams, ${ }^{6}$ Matthias Schmitt ${ }^{7}$
}

\begin{abstract}
- Additional material is published online only. To view, please visit the journal online (http://dx.doi.org/10.1136/ openhrt-2020-001389).
\end{abstract}

To cite: Yong GL, Weir-McCall J, Wilson M, et al. Research priorities in cardiovascular imaging. Open Heart 2020;7:e001389. doi:10.1136/ openhrt-2020-001389

Received 15 July 2020 Revised 14 August 2020 Accepted 17 August 2020

Check for updates

(C) Author(s) (or their employer(s)) 2020. Re-use permitted under CC BY-NC. No commercial re-use. See rights and permissions. Published by BMJ.

${ }^{1}$ Clinical Radiology, Edinburgh Royal Infirmary, Edinburgh, UK ${ }^{2}$ University of Cambridge School of Clinical Medicine, UK, Cambridge, UK

${ }^{3}$ General Surgery, Forth Valley

Royal Hospital, Larbert, UK

${ }^{4}$ Radiology, NHS Greater

Glasgow and Clyde, Glasgow, UK

${ }^{5}$ Clinical Radiology Royal

Bournemouth Hospital,

Bournemouth, UK

${ }^{6}$ Centre for Cardiovascular

Sciences, University of

Edinburgh, Edinburgh, UK

${ }^{7}$ North West Heart Centre,

Manchester University NHS

Foundation Trust, Manchester,

UK

Correspondence to

Dr Guo Liang Yong; d.yong@ nhs.net

\section{ABSTRACT}

Aim A modified Delphi approach was used to develop consensus opinion among British Society for Cardiac Imaging/British Society of Cardiac CT (BSCI/BSCCT) members in order to prioritise research questions in cardiovascular imaging.

Methods All members of the BSCI/BSCCT were invited to submit research questions that they considered to be of the highest clinical and/or academic priority in the field of cardiovascular imaging (phase 1). Subsequently a steering committee removed duplicate questions and combined questions of a similar theme by consensus agreement where appropriate. BSCI/BSCCT members were invited to rank the resulting research questions in two further iterative rounds (phases 2 and 3 ) to determine a final list of high-priority research questions.

Results A total of 111 research questions were submitted in phase 1 by $30 \mathrm{BSCl} / \mathrm{BSCCT}$ members. While there was a broad range of topics, from determining the optimal features/markers of the vulnerable plaque to investigating how cardiac imaging can best be used to maximise clinical outcomes and economic costs, multimodality imagingrelated $(n=44,40 \%)$ questions dominated the categories and coronary artery imaging $(n=40,36 \%)$ was the most common topic. Over two iterative rounds of prioritisation of these research questions, the original 111 were reduced to 75 questions in round 2 , and 25 in round 3 . From these 25 a final Top 10 list was distilled by consensus grouping. Conclusion This study has identified and ranked the top research priorities in cardiovascular imaging, as identified by the BSCI/BSCCT membership. This is a first step towards identifying the cardiovascular imaging research priorities within the UK and may assist researchers and funding bodies alike in setting priorities.

\section{INTRODUCTION}

Cardiovascular imaging (CI) has significantly enhanced the diagnosis of all forms of heart disease and is now often centre stage to the patient care pathway. Following rapid technological advancement the cardiovascular (CV) physician has access to a wide armamentarium of invasive and non-invasive imaging modalities, including invasive coronary angiography, echocardiography, CT, nuclear imaging and MRI. ${ }^{1}$ In the UK alone over 500000 noninvasive cardiac imaging examinations are performed every year, with an annual growth

\section{Key questions}

What is already known about this subject?

- Cardiovascular imaging has revolutionised the diagnosis and treatment of heart disease. Research resources should be deployed in areas likely to have the greatest clinical impact. A modified Delphi process can be used to develop a list of priorities by consensus from a group of experts.

What does this study add?

- Our survey aims to develop a list of high-priority clinical research questions in cardiovascular imaging using a modified Delphi approach to help focus future research.

How might this impact on clinical practice?

- This list of 10 high-priority research questions in cardiovascular imaging will facilitate funding applications and design high-quality collaborative research over the coming years.

rate of $3 \% .^{2}$ This is due to a growing body of evidence supporting its use as outlined in multiple national appropriateness and guideline documents covering a wide spectrum of heart diseases. ${ }^{3}$ Additionally, many research studies testing novel CV medicines and interventional therapies now use CI as either primary or secondary outcomes, or as surrogate markers. However, consensus opinion on the major research priorities for $\mathrm{CI}$ in the UK is currently unknown.

British CV research, and specifically cardiovascular imaging research (CIR) is world leading, yet is facing multiple challenges not least the potential loss of access to significant funding sources from European research funding bodies such as the Horizon programme. It is in this context that the British Heart Foundation (BHF) has engaged with multiple stakeholders including the British Cardiovascular Society (BCS) with all its affiliated Societies (of which the British Society for Cardiac Imaging/ British Society of Cardiac CT (BSCI/BSCCT) is one member) and established the BHFClinical Research Collaborative (CRC). The 
BHF-CRC aims to act as a catalyst for CV research collaborations by providing enabling infrastructure, simplifying and democratising $\mathrm{CV}$ research. It was in the context of the founding meeting of the BHF-CRC that the research subcommittee of the BSCI/BSCCT decided to formulate its own research priorities.

A modified Delphi process can be used to develop a list of priorities by consensus from a group of experts, specifically its own membership. This method has been extensively used by a number of surgical specialties ${ }^{4-7}$ to develop research priorities and importantly is also the method used to formulate the Royal College of Radiology iREFER guidelines. ${ }^{8}$ To date there has been no comprehensive undertaking to determine research priorities in the subspecialty of CI. Such information will be invaluable to centres involved in CIR and funding bodies alike. Specifically, if taken up by other BHF-CRC-affiliated and/ or BCS-affiliated groups it could be the first step towards creating a comprehensive picture of $\mathrm{CV}$ research priorities. In addition, this information will facilitate multicentre collaboration on important research topics.

This study, organised by the BSCI/BSCCT, aims to develop a Top 10 list of clinically focused CV research questions that are thought to have immediate translational potential to advance CV care.

\section{METHODS}

A three-phase modified Delphi process was undertaken (figure 1) using established methodology, as previously described. ${ }^{4-7910}$ This included the submission of research questions by members of the BSCI/BSCCT followed by two distinct rounds of prioritisation and question ranking.

\section{Phase 1}

A steering committee (GLY, JWM, MCW, MW, MS) was formed from the research subcommittee of the BSCI/ BSCCT executive committee. The steering committee was composed of cardiologists, radiologists and a lay representative with previous experience of the modified Delphi process.

All BSCI/BSCCT members were invited by email to submit research questions relating to CI via an online survey form (http://surveymonkey.co.uk). There was no limit on the number of research questions that an individual could submit. The survey remained open for 2 months with two reminder emails sent to the BSCI/ BSCCT membership during this period.

Submitted questions were collated and classified by the steering committee based on modality and area of research. Modality classification was divided into the following subcategories: (1) CT, (2) MRI, (3) nuclear medicine, and (4) multimodality. Area of research classification included the following subcategories: (1) coronary, (2) myocardium, (3) structural, (4) valvular, (5) cardio-oncology, (6) vascular, (7) congenital, (8) harm/ side effects, (9) outcomes, (10) research technique, (11) technological advancement, (12) economic impact,

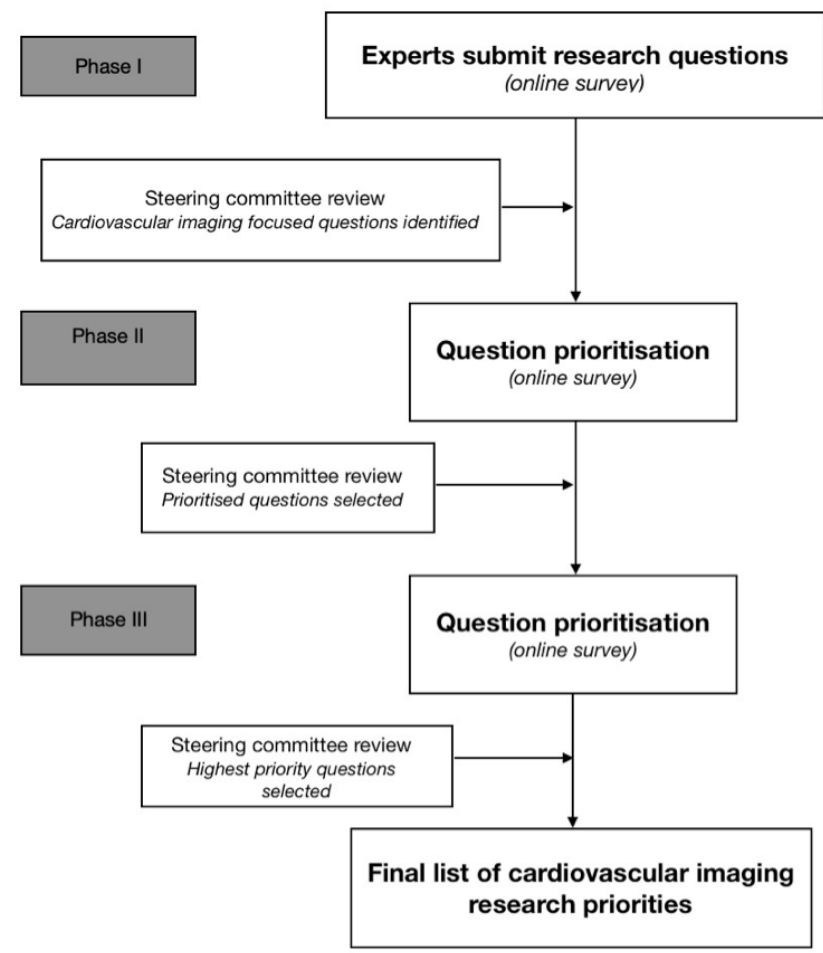

Figure 1 Modified Delphi process for cardiovascular imaging research prioritisation.

(13) artificial intelligence, and (14) other/general. Any disagreements regarding categorisation were resolved by consensus.

Duplicate questions were removed. Similar questions were combined following discussion by the steering group into a single question. Care was taken not to alter the meaning of the original questions when questions were combined or rephrased.

\section{Phase 2}

BSCI/BSCCT members were invited by email to prioritise the CIR questions identified during phase 1. Using an online survey form (http://surveymonkey.co.uk) research questions were presented in a random order for each respondent . Respondents were asked to score each question based on their own perception of the clinical importance using a 5-point Likert scale (1-lowest priority to 5-highest priority). The survey remained open for 2 months with two email reminders sent to all BSCI/BSCCT members.

The results of the round 2 prioritisation were reviewed by the steering committee and a 'cut-off' point agreed by consensus in order to identify the highest scoring 25 questions.

\section{Phase 3}

BSCI/BSCCT members were invited by email to perform a final round of prioritisation on the 25 questions identified in phase 2 using an online survey form (http:// surveymonkey.co.uk). Research questions were provided 


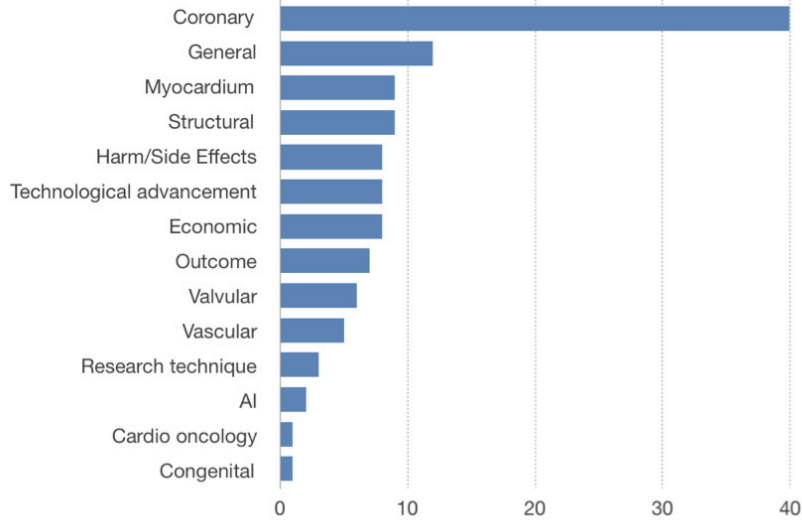

Figure 3 The range of topics referred to the submitted research questions. Al, artificial intelligence.

in a random order for each respondent. Using the same 5-point Likert scale respondents were asked to score each question on the perceived clinical importance. The survey remained open for 2 months with two reminder emails sent to all BSCI/BSCCT remembers. Results were reviewed by the steering committee to identify the final list of prioritised questions.

\section{Statistical analysis}

Weighted average scores were generated by SurveyMonkey for each question when each phase of the survey was closed. These weights were downloaded from the SurveyMonkey website in a Microsoft Excel spreadsheet format. The weighted averages were used to prioritise the research questions during each of the phases of the survey, with questions with the highest weighted average having the highest priority.

\section{RESULTS}

One hundred and eleven research questions were submitted by $30 \mathrm{BSCI}$ /BSCCT members in phase 1 , representing participation of $\sim 7 \%$ of the BSCI/BSCCT membership. Research questions regarding multimodality imaging were the most frequent $(n=44,40 \%)$, followed by those regarding CT ( $n=33,30 \%$, figure 2$)$. The most frequent research topic in the submitted questions was coronary artery disease $(n=40,36 \%$, figure 3$)$.

The submitted questions were reviewed by the steering committee and duplicate or similar questions were combined or amended, leaving 75 questions available for prioritisation in phase 2. Thirty-eight BSCI/BSCCT members $(9 \%)$ participated in the phase 2 research question prioritisation. The mean weighted average question score was 3.19 , with a range from 2.56 to 3.84 . The complete question list in the order of priority is shown in online supplemental appendix 1 .

A cut-off value for the weighted average was set as 3.31 in order to identify the top 25 research questions for prioritisation in phase 3. Forty BSCI/BSCCT members (10\%) participated in phase 3 research question prioritisation.

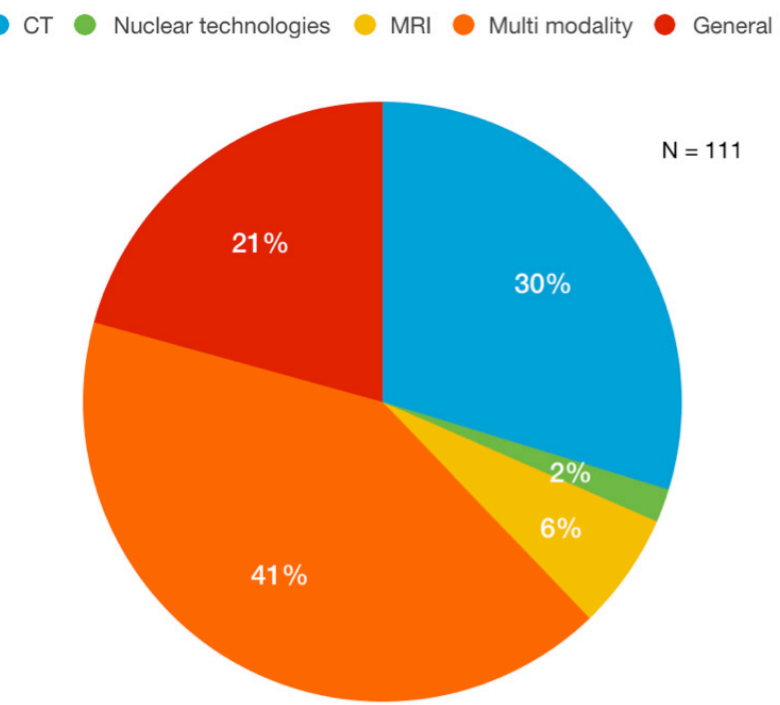

Figure 2 Imaging modalities referred to the submitted research questions.

The mean weighted average question score was 3.54, with a range from 3.13 to 3.93 . The top 25 research questions ordered by priority are shown in table 1 .

A cut-off value for the weighted average was set as 3.60 in order to identify the final top 10 research questions in CI . Of these 10 questions, $6(60 \%)$ related to stable coronary artery disease, $2(20 \%)$ to acute coronary syndrome, $1(10 \%)$ to arrhythmias and $1(10 \%)$ to a wider question on the incorporation of multimodality imaging into clinical practice (table 2).

\section{DISCUSSION}

This study has produced and ranked high-priority research questions related to non-invasive CVI as defined by the BSCI/BSCCT expert membership. To our knowledge, this is the first time that such a project has been undertaken in the field of CI. It is hoped and anticipated that this undertaking will stimulate CV research collaboration within (but also beyond) the BSCI/BSCCT and inform researchers and research funding bodies alike.

The top 10 priority list has a strong emphasis on coronary artery disease (priorities 1, 2, 5, 6, 7, 8, 10). This was a consistent theme from the submitted questions in phase 1 through to the final prioritisation. This is unsurprising as the investigation of stable coronary artery disease and its acute presentation represents a significant clinical workload for both cardiologists and radiologists involved in CI in the UK. ${ }^{11}$ The Top 10 list also includes questions regarding optimising of imaging protocols, choice of imaging strategies, improving patient outcomes and assessing economic impact (priorities 2, 5, 6, 8, 10).

It needs to be emphasised that participants were asked to rank questions in order of their clinical priority. The study therefore concentrated on translational research spectrum as opposed to the preclinical/bench spectrum. 


\begin{tabular}{|c|c|}
\hline Priority & Research question \\
\hline 1 & Is there a combination of stenosis/CTFFR/plaque features that identify a situation where the benefit of a stent outweighs its risks? \\
\hline 2 & How can we best target cardiac imaging to optimise its yield in terms of outcomes and economic costs? \\
\hline 3 & Is there a mortality/morbidity reduction through the wider use of CTCA? \\
\hline 4 & What is the optimum imaging/investigative strategy in acute coronary syndromes? \\
\hline 5 & What are the outcomes of CTCA use in low-risk ACS patients? \\
\hline 6 & How can we limit increases in downstream costs and healthcare utilisation after CTCA? \\
\hline 7 & What are the optimal features/markers of the vulnerable plaque? \\
\hline 8 & What is the role of CTFFR in clinical practice? \\
\hline 9 & Can we identify and characterise biomarkers of sudden cardiac death/arrhythmias in order to develop better risk stratification tools? \\
\hline 10 & What is the economic impact of CTFFR in routine practice? \\
\hline 11 & Can we standardise advanced MRI techniques (eg, late gadolinium enhancement quantification, mapping)? \\
\hline 12 & How do different cardiac imaging strategies affect downstream testing? \\
\hline 13 & $\begin{array}{l}\text { How useful are TAVI (Transcatheter Aortic Valve Implantation) CTs in management decisions when many people who are worked up don't } \\
\text { end up getting TAVI, is there a more cost-effective strategy to predict who needs TAVI CT? }\end{array}$ \\
\hline 14 & Can cardiovascular imaging be used to predict/improve outcomes in cardiomyopathy imaging? \\
\hline 15 & How can we reduce the impact of calcification on CTCA diagnostic accuracy, in a radiation and time-efficient manner? \\
\hline 16 & Can we use artificial intelligence to enable decision support tools for the use of cardiovascular imaging? \\
\hline 17 & What is the optimum follow-up interval for imaging of cardiovascular disease (eg, aneurysms, dissection)? \\
\hline 18 & Can CTCA replace functional imaging for stable angina? \\
\hline 19 & Can we develop methods to improve accuracy in CTCA assessment of in-stent disease? \\
\hline 20 & What is the role of artificial intelligence in cardiovascular disease? \\
\hline 21 & Is there a role for early use of cardiac CT in confirmed/high-risk ACS? \\
\hline 22 & What are the barriers to the implementation of evidence-based imaging strategies in cardiovascular imaging? \\
\hline 23 & Which patients do not need or derive no benefit from cardiovascular imaging? \\
\hline 24 & Do any advanced imaging modalities improve outcome in dilated cardiomyopathy? \\
\hline 25 & Has the change of the NICE guidance resulted in more inappropriate CTCA referrals? \\
\hline
\end{tabular}

BSCI/BSCCT, British Society for Cardiac Imaging/British Society of Cardiac CT; NICE, National Institute for Health and Care Excellence.

This is relevant and justified in so far as the BSCI/BSCCT membership is mainly composed of clinically active practitioners and several other BCS-affiliated groups exist (British Society for Cardiovascular Research, British Atherosclerosis Society, Society for Cardiological Science and Technology, to name just a few) dedicated to preclinical and/or bench side science.

Indeed, the BSCI/BSCCT membership is a diverse group of clinically focused radiologists and cardiologists from throughout the UK and Ireland. The BSCI/BSCCT is the specialist interest group for CI of the Royal College of Radiologists and is also a member of the Imaging Council of the BCS. Although the membership does include many practitioners who use multiple modalities it has a particular focus on CT as there are other UK imaging societies specifically dedicated to CV MRI and cardiac nuclear imaging - that is, the British Society of Cardiovascular Magnetic Resonance and British Nuclear Cardiology Society, respectively. Therefore, by definition this exercise has produced a focused and unquestionably biased result which was inherent to the study design.
As mentioned above it is hoped this study is the first piece of the wider puzzle. Furthermore, in addition to other affiliated groups and clinical stakeholders, future efforts should include members of the public given the increasing emphasis on patient and public involvement to determine where future $\mathrm{CV}$ research should be focused. ${ }^{12}$

A further limitation of the study is that only approximately $10 \%-15 \%$ of the BSCI/BSCCT membership participated in the various iterations of the study. Similar studies using the modified Delphi methodology have demonstrated a similar response rate. ${ }^{6}$ Therefore, although low, this is probably a fair reflection of the engagement such an exercise can deliver. Lastly, this study was conducted in the pre-COVID-19 era and it is acknowledged that research prioritise since they have significantly shifted to address the not inconsiderable acute and long-term $\mathrm{CV}$ aspects of this global pandemic.

This study has identified and ranked the top research priorities in the field of CI as defined by the BSCI/BSCCT membership in the pre-COVID-19 era. The emerging theme has a strong emphasis on coronary artery disease 
Table 2 Top 10 BSCI/BSCCT research priorities in descending order

\begin{tabular}{ll}
\hline Priority & Research question \\
\hline 1 & $\begin{array}{l}\text { Is there a combination of stenosis/CTFFR/plaque features } \\
\text { that identify a situation where the benefit of a stent } \\
\text { outweighs its risks? }\end{array}$ \\
\hline 2 & $\begin{array}{l}\text { How can we best target cardiac imaging to optimise its } \\
\text { yield in terms of outcomes and economic costs? }\end{array}$ \\
\hline 3 & $\begin{array}{l}\text { Is there a mortality/morbidity reduction through the wider } \\
\text { use of CTCA? }\end{array}$ \\
\hline 5 & $\begin{array}{l}\text { What is the optimum imaging/investigative strategy in } \\
\text { acute coronary syndromes? }\end{array}$ \\
\hline 6 & $\begin{array}{l}\text { What are the outcomes of CTCA use in low-risk ACS } \\
\text { patients? }\end{array}$ \\
\hline 7 & $\begin{array}{l}\text { How can we limit increases in downstream costs and } \\
\text { healthcare utilisation after CTCA? }\end{array}$ \\
\hline 8 & What are the optimal features/markers of the vulnerable \\
\hline 9 & $\begin{array}{l}\text { What is the role of CTFFR in clinical practice? } \\
\text { cardiac death/arrhythmias in order to develop better risk } \\
\text { stratification tools? }\end{array}$ \\
\hline 10 & What is the economic impact of CTFFR in routine practice? \\
\hline ACS, acute coronary syndrome; BSCl/BSCCT, British Society for \\
tomography coronary angiogram; CTCFFR, computed tomography \\
fractional flow reserve.
\end{tabular}

research and identification of the vulnerable patient (and plaque). It is hoped that this although biased (through the lens of the BSCI/BSCCT membership) piece of work will stimulate sister societies and other BHF-CRC and BCS-affiliated groups to undertake similar if not identical exercises so that the funding researchers, funding and government bodies gain a comprehensive picture of the UK CV research priorities and needs.

Acknowledgements We acknowledge the time and effort put into providing research questions and performing the survey prioritisation by the BSCI/BSCCT membership. This includes Agha Haider, Alastair Moss, Alexia Ferrugia, Allanah Barker, Amr Kandil, Andrew D'Silva, Andrew Kelion, Andrew Mitchell, Anna Beattie, Anna John, Aparna Despande, Azhar Khokhar, Benjamin Hudson, Bobby Agrawal, Buzan Teo, Carl Roobottom, Cheng Sheng Low, Chris Steadman, Davinda Karunaratne, Derek Connolly, Ed Neil-Gallacher, Fragkiadski Chrysoula, Giles Roditi, Guilietta Benedetti, James Shambrook, Jamie Kitt, John Byrn, John Purvis, John-Paul Carpenter, Jonathan Carl Luis Rodrigues, Jonathan Weir-McCall, Kavin, Jayawardhana, Kingsley Nwafor, Konstantinos Kaloudis, Leon Menezes, Matthias Schmitt, Michelle Williams, Mona Sriharan, Nicholas Screaton, Rajai Ahmad, Ramabala Vuyyuru, Rhidian Shelton, Robert Huggett, Shaimaa Habib, Sharon
Wilson, Subramanya Upadhyaya, Sue Thomas, Sunil Nair, Thomas Semple, Victor Voon.

Contributors GLY, JWM, MCW, MW and MS formed the steering group, ran the study and analysed the results. GLY wrote the manuscript, which was revised and edited by JWM, MCW, MW, MS, GHR and RB. All authors provided advice, intellectual input and approved the final manuscript. MS provided a supervisory role, reviewed and finalised the manuscript.

Funding The authors have not declared a specific grant for this research from any funding agency in the public, commercial or not-for-profit sectors.

Competing interests None declared.

Patient consent for publication Not required.

Provenance and peer review Not commissioned; externally peer reviewed.

Data availability statement All data relevant to the study are included in the article or uploaded as supplementary information.

Open access This is an open access article distributed in accordance with the Creative Commons Attribution Non Commercial (CC BY-NC 4.0) license, which permits others to distribute, remix, adapt, build upon this work non-commercially, and license their derivative works on different terms, provided the original work is properly cited, appropriate credit is given, any changes made indicated, and the use is non-commercial. See: http://creativecommons.org/licenses/by-nc/4.0/.

\section{ORCID iDs}

Guo Liang Yong http://orcid.org/0000-0002-4080-3559

Jonathan Weir-McCall http://orcid.org/0000-0001-5842-842X

\section{REFERENCES}

1 de Roos A, Higgins CB. Cardiac radiology: centenary review. Radiology 2014;273:S142-59.

2 NHS England and NHS Improvement. Diagnostic imaging dataset 2019-20 data. Available: https://www.england.nhs.uk/statistics/wpcontent/uploads/sites/2/2019/12/Provisional-Monthly-DiagnosticImaging-Dataset-Statistics-2019-12-19-1.pdf

3 National Institute for Health and Care Excellence. Acute coronary syndromes in adults; 2014.

4 Tiernan J, Cook A, Geh I, et al. Use of a modified Delphi approach to develop research priorities for the association of coloproctology of great britain and ireland. Colorectal Dis 2014;16:965-70.

5 Wilson MSJ, Knight S, Vaughan-Shaw P, et al. A modified AUGIS Delphi process to establish research priorities in bariatric and metabolic surgery. Clin Obes 2020;10:e12344.

6 Henderson J, Reid A, Jain A. Use of a modified BAPRAS Delph process for research priority setting in plastic surgery in the UK. $J$ Plast Reconstr Aesthet Surg 2018;71:1679-81.

7 Knight SR, Pathak S, Christie A, et al. Use of a modified Delphi approach to develop research priorities in HPB surgery across the United Kingdom. HPB 2019;21:1446-52.

8 iRefer, Royal College of Radiologists. Making the best use of clinical radiology [Version 8.0.1], 2020. Available: https://www.irefer.org.uk

9 Wilson MSJ, Vaughan-Shaw P, Boyle C, et al. A modified AUGIS Delphi process to establish future research priorities in benign upper gastrointestinal surgery. World J Surg 2020;44:1216-22.

10 Wilson MS, Blencowe NS, Boyle C, et al. A modified Delphi process to establish future research priorities in malignant oesophagogastric surgery. Surgeon 2019. doi:10.1016/j.surge.2019.11.003. [Epub ahead of print: 16 Dec 2019].

11 Bhatnagar P, Wickramasinghe $\mathrm{K}$, Williams $\mathrm{J}$, et al. The epidemiology of cardiovascular disease in the UK 2014. Heart 2015;101:1182-9.

12 McNair AGK, Heywood N, Tiernan J, et al. A national patient and public colorectal research agenda: integration of consumer perspectives in bowel disease through early consultation. Colorectal Dis 2017;19:075-85. 